\title{
Congenitally corrected transposition of the great vessels associated with morphological right ventricular non-compaction presenting with supraventricular tachycardia
}

\author{
Ajit Pal Singh, Soumya Patra, Navin Agrawal, Ravindranath K Shankarappa
}

Department of Cardiology Sri Jayadeva Institute of Cardiovascular Sciences and Research, Bengaluru, Karnataka, India

\section{Correspondence to} Dr Navin Agrawal,

drnavinagrawal@gmail.com

\section{DESCRIPTION}

A 25-year-old man presented to the emergency department with acute onset palpitation. He had a history of four to five similar episodes in the past 2 months, which had resolved on their own. ECG showed supraventricular tachycardia (SVT) with a rate of $170 / \mathrm{min}$ (figure 1 ). He was treated with intravenous adenosine which reverted the tachycardia. Transthoracic echocardiogram was attempted but an adequate window could not be obtained as the patient was obese. Only the spatial relationship of the two great vessels in the form of malposition could be made out which confirmed the aorta was left and anterior and the pulmonary artery was right
To cite: Singh AP, Patra $S$ Agrawal $\mathrm{N}$, et al. BMJ Case Rep Published online:

[please include Day Month Year] doi:10.1136/bcr-2013-

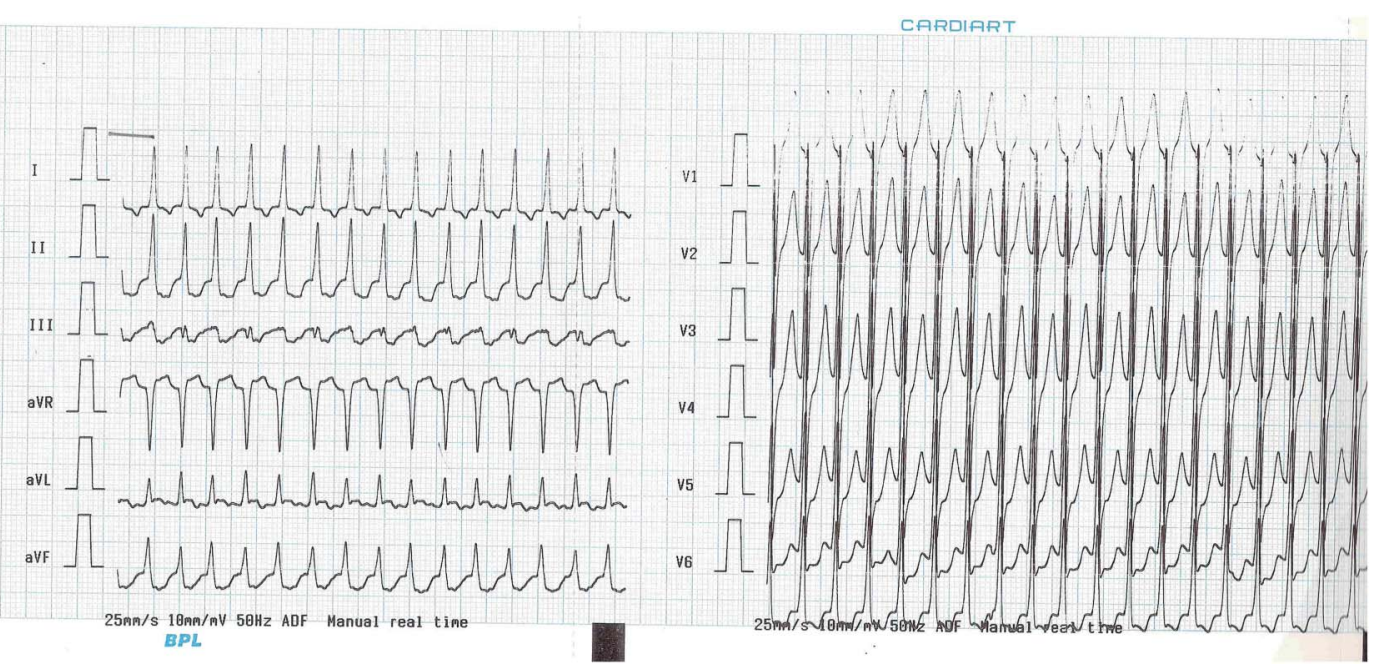

Figure 1 ECG showed supraventricular tachycardia.

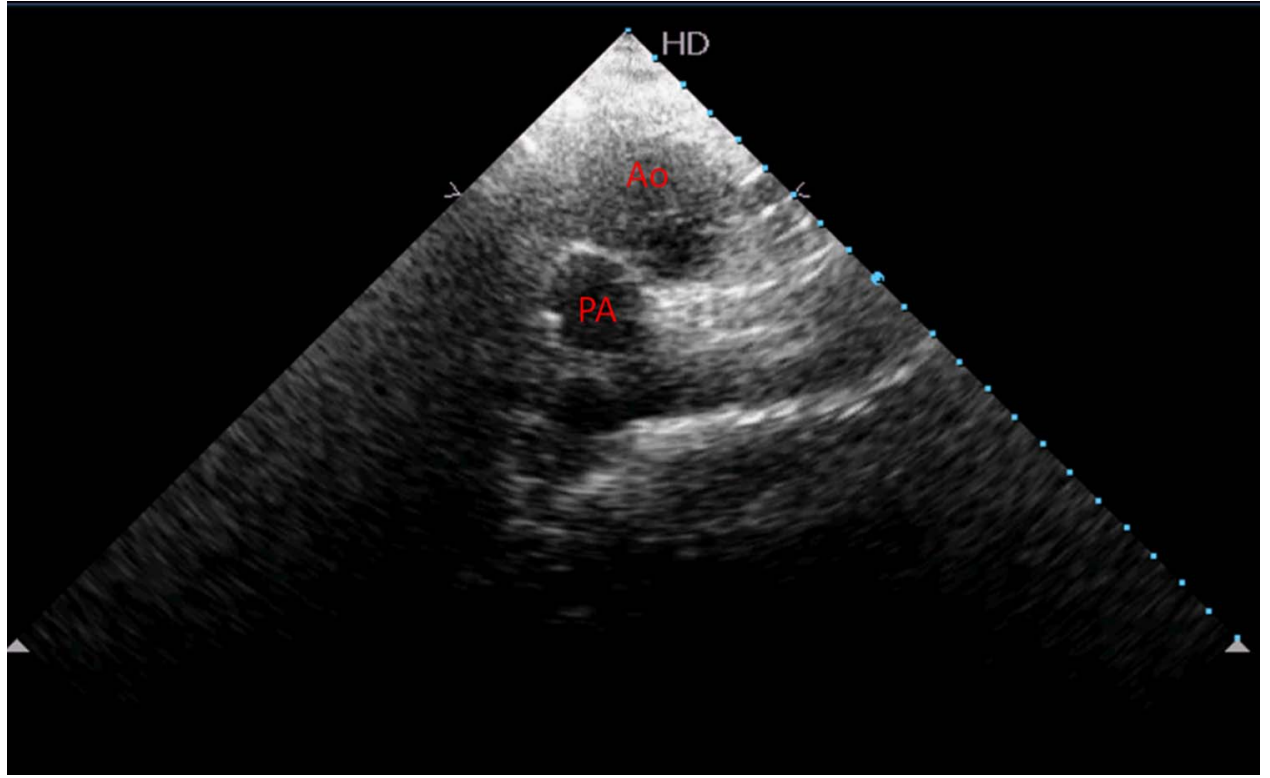

Figure 2 Transthoracic echocardiogram showed the spatial relationship of the two great vessels where aorta on the left and anterior of the pulmonary artery. 


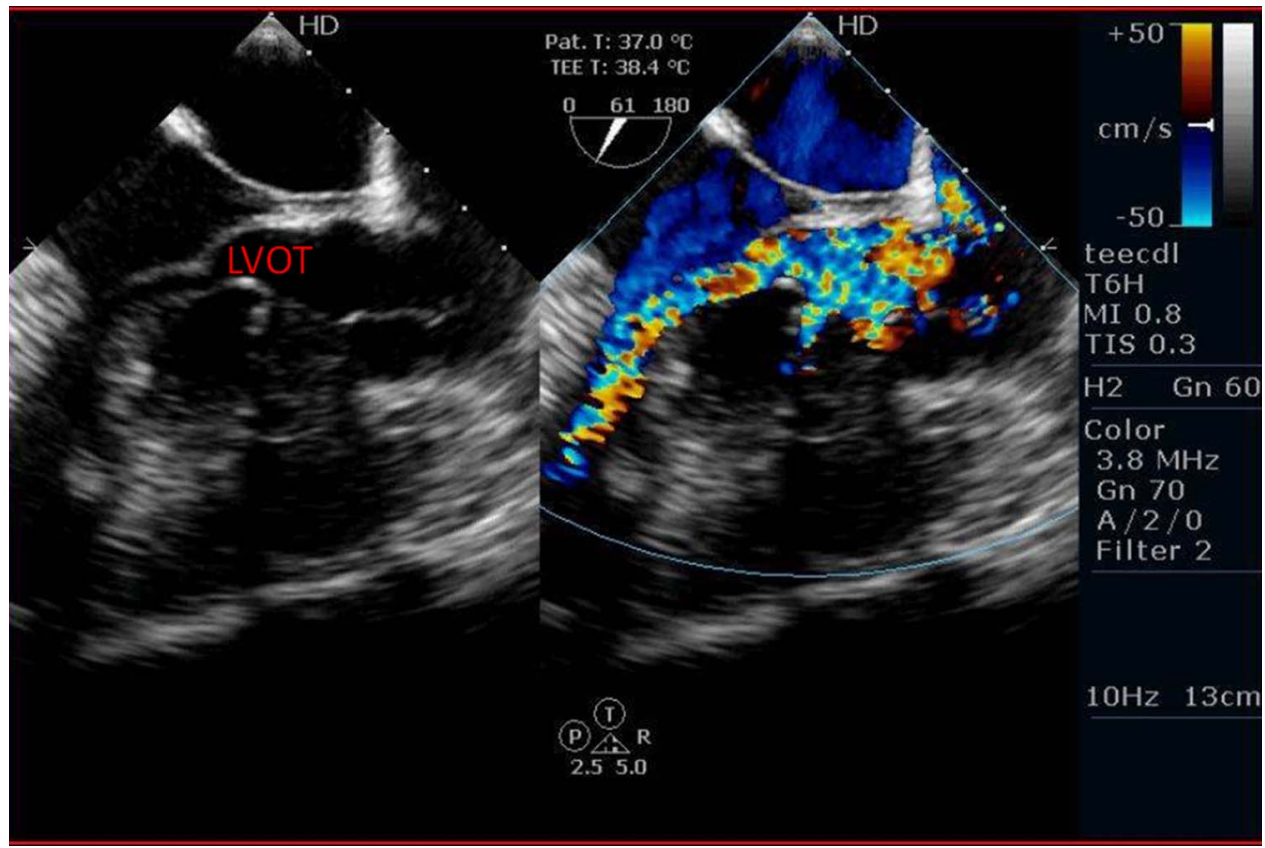

Figure 3 Transthoracic echocardiogram suggested a diagnosis of corrected transposition of great vessels with dynamic left ventricular outflow tract obstruction.

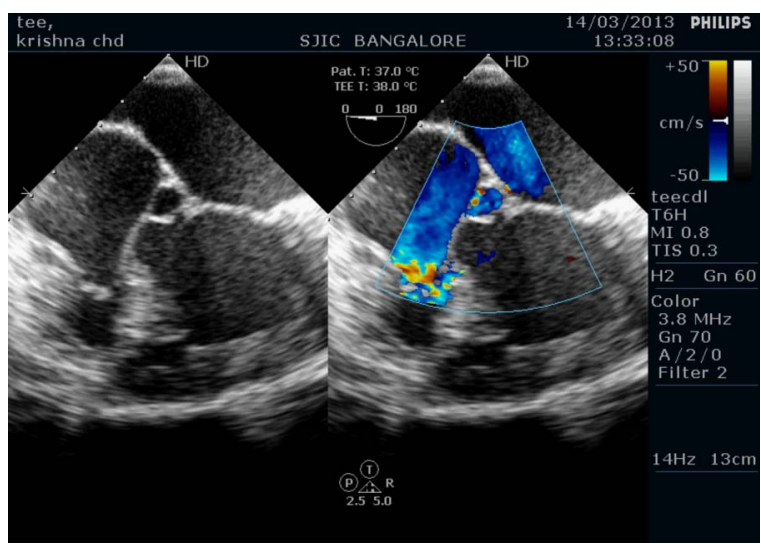

Video 1 TEE suggested a diagnosis of c-TGV with dynamic left ventricular outflow tract obstruction. and posterior (figure 2). The visceral situs was normal. Hence a transoesophageal echocardiogram was performed which suggested a diagnosis of corrected transposition of great vessels (c-TGV) with dynamic left ventricular outflow tract obstruction with a peak gradient of $20 \mathrm{~mm} \mathrm{Hg}$ (figure 3, video 1). Dysfunction of the systemic ventricle (morphological right ventricle, MRV) was also noted. Cardiac MRI confirmed the diagnosis as c-TGV with small perimembranous ventricular septal defect and non-compaction of the MRV with a ratio of the noncompacted to compacted segment greater than 2.3 as per the present criteria $^{1}$ (figure $4 \mathrm{~A}, \mathrm{~B}$ ).

There are only a few case reports in the literature where c-TGV has been associated with non-compaction of $M^{2} V^{2}$ and few cases have been reported with SVT. ${ }^{3}$ In our case, there was presence of SVT and non-compaction of MRV in a case of c-TGV.

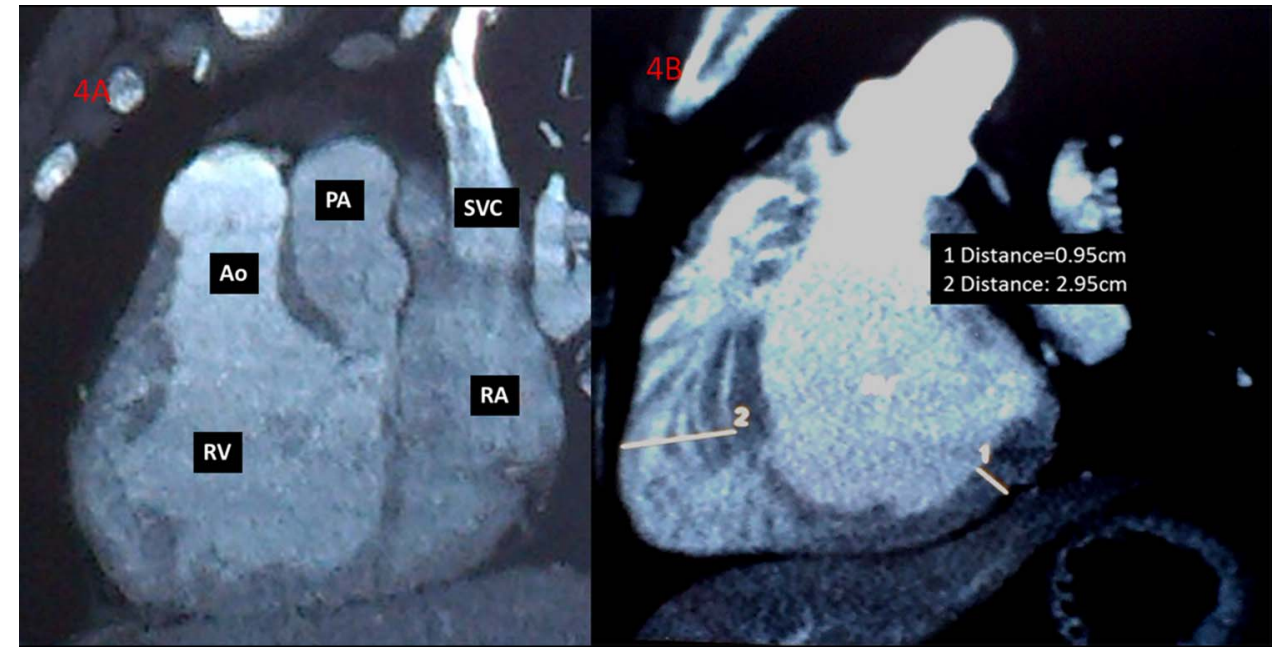

Figure 4 ( $A$ and $B$ ) CMRI showed the relationship suggesting corrected transposition of great vessels and confirmed the presence of non-compaction of morphological right ventricle. 


\section{Learning points}

- Congenitally corrected transposition of great arteries (TGA) can be associated with non-compaction of morphological right ventricle.

- Supraventricular tachyarrhythmias are a rare occurrence with corrected transposition of great vessels .

- Cardiac MRI is most reliable investigation to diagnose non-compaction.

Contributors All authors involved in the management of this patient and approved the final version of this manuscript.
Competing interests None.

Patient consent Obtained.

Provenance and peer review Not commissioned; externally peer reviewed.

\section{REFERENCES}

1 Petersen SE, Selvanayagam JB, Wiesmann F, et al. Left ventricular non-compaction. Insights from cardiovascular magnetic resonance imaging. J Am Coll Cardiol 2005;46:101-5.

2 Kharge J, Prasad MR, Ramegowda RT. An unusual case of congenitally corrected transposition of the great arteries associated with noncompaction-like remodeling of the morphological right ventricle. Echocardiography 2011;28:E212-14.

3 Eisenberger M, Fox DJ, Earley MJ, et al. Atrioventricular node reentrant tachycardia ablation in a patient with congenitally corrected transposition of the great vessels using the CARTO mapping system. J Interv Card Electrophysiol 2007;19:129-32.

Copyright 2013 BMJ Publishing Group. All rights reserved. For permission to reuse any of this content visit http://group.bmj.com/group/rights-licensing/permissions.

BMJ Case Report Fellows may re-use this article for personal use and teaching without any further permission.

Become a Fellow of BMJ Case Reports today and you can:

- Submit as many cases as you like

- Enjoy fast sympathetic peer review and rapid publication of accepted articles

- Access all the published articles

- Re-use any of the published material for personal use and teaching without further permission

For information on Institutional Fellowships contact consortiasales@bmjgroup.com

Visit casereports.bmj.com for more articles like this and to become a Fellow 